\title{
Physiological Responses of Coral Reef Species to Emerging Threats of Anthropogenic Climate
} Change

\section{RABIA MAHMOOD}

Department of Biological Sciences, University of Toronto Scarborough, Canada Department of Psychology, University of Toronto Scarborough, Canada

\section{Abstract}

Anthropogenic climate change is a threat to countless species and ecosystems around the world, including the coral reefs. Coral reefs provide habitat to thousands of species and play a large role in maintaining biological diversity. They are severely threatened by the rapidly changing climate, particularly due to increasing sea surface temperatures and ocean acidification. Constant exposure to these environmental stressors can lead to bleaching and reduction in coral calcification rates, which can severely compromise the health and distribution of the coral reefs. This paper discusses new research on physiological responses of various organisms that make up the coral reefs, particularly coral and zooxanthellae species, to these threats. Research over the past decade has identified several species that are resilient in the face of climate change as well as areas that could serve as temporary refugia during this unprecedented situation. This research can be incorporated into current conservation practices for the development of conservation and restoration strategies to better protect the coral reefs.

Keywords: ocean acidification, temperature-induced bleaching, coral calcification

\section{Introduction}

Anthropogenic climate change is a threat to countless species and ecosystems around the world. Human activities such as deforestation, overfishing, overhunting, and increased carbon dioxide $\left(\mathrm{CO}_{2}\right)$ emissions contribute to increases in greenhouse gas emissions and temperatures, which are key drivers of climate change (Hoegh-Guldberg \& Bruno,
2010; von Schuckmann et al., 2016). The rise in greenhouse gas emissions has led to an increase in global temperatures (National Centers for Environmental Information, 2020). Since 1981, the global annual temperatures have increased at an average rate of $0.18^{\circ} \mathrm{C}$ per decade. Additionally, the five warmest years in 1880-2019 have all occurred since 2015, 
which emphasizes the severity of the problem. The effects of anthropogenic climate change extend to seas and oceans. More than $90 \%$ of the heat energy is absorbed by oceans, leading to an increase in sea surface temperature (SST; HoeghGuldberg \& Bruno, 2010; von Schuckmann et al., 2016). Particularly, the ocean heat content has been increasing, with the five highest increases in the heat content also occurring in the last five years (i.e. 20152019; National Centers for Environmental Information, 2020). Moreover, ocean pH has been declining as a result of increased $\mathrm{CO}_{2}$ emissions (Jiang et al., 2019). Oceans absorb approximately $30 \%$ of the total $\mathrm{CO}_{2}$. This has led to a decrease in the $\mathrm{pH}$ of water bodies by 0.02 units per decade which was projected to accelerate to a 0.04 unit decrease in $\mathrm{pH}$ by 2020 , leading to ocean acidification (Hoegh-Guldberg \& Bruno, 2010; Jiang et al., 2019).

One ecosystem that has been increasingly threatened by anthropogenic climate change is the coral reefs (Heron et al., 2016). Coral reefs are mainly found in tropical seas and have the highest biodiversity among all marine ecosystems (Mies et al., 2018). They provide habitat to about a quarter of the world's marine species (Guan et al., 2020). They also provide many important services such as tourism, fishing, pharmaceuticals, and coastal protection (Hoegh-Guldberg, 1999; Mies et al., 2018). Unfortunately, increasing temperatures and ocean acidification have made the reefs vulnerable to climate change through temperature-induced bleaching and reduction in coral calcification (See Fig. 1; Putnam \& Gates, 2015; Scavia et al., 2002). The health and distribution of coral reefs will be compromised unless warming is mitigated (Hoegh-Guldberg, 1999).

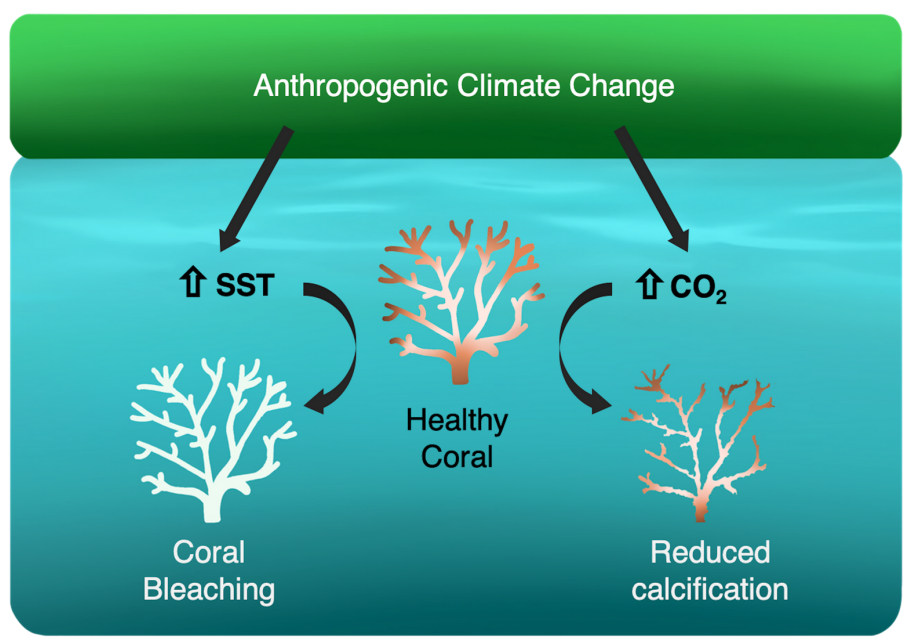

Figure 1. Effects of anthropogenic climate change on coral reefs.

Increased sea surface temperature (SST) is associated with bleaching, while ocean acidification due to increasing $\mathrm{CO}_{2}$ concentrations is associated with reduction in calcification (Mies et al., 2018; Mollica et al., 2018).

This paper discusses the major threats to the survival of the coral reefs and their responses to these threats. It also discusses new research on the resilience and persistence of different coral and zooxanthellae species when exposed to various environmental stressors. This research can be integrated into current conservation strategies to better protect coral species in a rapidly changing climate. 
Symbioses in Coral Reefs - Corals and Zooxanthellae

The reefs are made up of several organisms, but reef-building corals compose the heart of this ecosystem (Mollica et al., 2018). Coral reefs are highly productive, supporting thousands of species, mainly due to the symbiosis between corals and zooxanthellae. The zooxanthellae (Symbiodinium spp.) are a highly diverse group of organisms that provide corals with up to $90 \%$ of their energy (Heron et al., 2016). Corals receive photosynthetic products such as sugars and amino acids, and provide the zooxanthellae with crucial plant nutrients, including ammonia and phosphate (HoeghGuldberg, 1999). These symbionts also facilitate calcium-deposition in corals, allowing them to create their skeleton or hard structure (Mies et al., 2018). Thus, the close mutualism between these organisms is critical to the persistence of coral reefs.

\section{Climate Change and Threats to Coral Reefs}

Increasing Temperatures and Coral Bleaching. Tropical seas have undergone rapid warming in the last 100 years (Hoegh-Guldberg, 1999). Over the past 18,000 years, mean sea surface temperature (SST) in the tropics has varied by less than $2^{\circ} \mathrm{C}$. However, at the current rate, SST is expected to increase by $1-2^{\circ} \mathrm{C}$ by 2100 due to increasing concentrations of greenhouse gases (Heron et al., 2016).
The increase in SST can lead to a breakdown in coral-zooxanthellae symbiosis. Thermal stress can induce corals to expel their zooxanthellae or cause the zooxanthellae to lose their photosynthetic pigments, which is known as the bleaching phenomenon (See Fig. 1; Mies et al., 2018). Constant exposure to elevated SST leads to the production of reactive oxygen species, which can cause cellular damage to the host coral species and their symbionts, leading to the expulsion of the zooxanthellae. The loss of photosynthetic pigments makes the coral tissue transparent and exposes the white aragonite skeleton of the corals (Mies et al., 2018). Long-term impacts of bleaching include reduced reef rugosity, loss of coral cover, reduced biodiversity, and local extinction of coral species (Heron et al., 2016). Thus, climate change severely affects corals as well as the organisms and various industries supported by coral reefs.

Hillyer et al. (2016) provide experimental support for this. They exposed sea anemone, a model species for coral, and its dinoflagellate symbiont to an elevated temperature of $32^{\circ} \mathrm{C}$ for 6 days. They observed that exposure to elevated temperatures led to the breakdown of symbiosis (i.e. bleaching). It led to changes in the metabolite profiles of both organisms, which were associated with a decline in essential activities, such as carbon fixation, and responses to thermal and oxidative stress. The researchers concluded that prolonged exposure to 
elevated temperatures can negatively affect the functional coral-zooxanthellae symbiosis (Hillyer et al., 2016).

Elevated SST has led to several mass coral bleaching events (Heron et al., 2016). Six major episodes of coral bleaching have occurred since 1979, and the resulting coral mortality has affected local and global coral reefs (Hoegh-Guldberg, 1999). Additionally, the global percentage of reefs impacted by bleaching-level thermal stress tripled between 1985 to 2012, with an observable increase in coral bleaching. During bleaching events, entire reef systems lose almost all their corals with no chance of recovery. As SST increases, bleaching events are expected to become more frequent and severe (Heron et al., 2016). Climate models project that bleaching events would become annual by 2050 in most oceans, with around $98 \%$ of reefs expected to be exposed to bleaching-level thermal stress every year (Heron et al., 2016; Hoegh-Guldberg, 1999). This indicates that the coral reefs may not be able to recover if the temperatures keep increasing. This also suggests that the current conservation efforts have not been fully successful at protecting the coral reefs, indicating a need for more research as well as the integration of new research in current conservation strategies.

\section{Ocean Acidification and Declining Coral Calcification. An increase in $\mathrm{CO}_{2}$} concentrations in the water bodies is associated with a decrease in calcium carbonate concentrations and $\mathrm{pH}$, leading to ocean acidification (Scavia et al., 2002). The surface ocean $\mathrm{pH}$ is projected to decrease by an average of approximately 0.33 units under a business-as-usual scenario from 2000 to 2100 (Jiang et al., 2019), which is about three times the rate of the $\mathrm{pH}$ decrease from 1770 to 2000 ( 0.11 units). Additionally, seawater carbonate concentration is projected to decline by around $100 \mu \mathrm{mol} / \mathrm{kg}$ by 2100, which is associated with an approximate $48 \%$ decrease in the precipitation rate of aragonite, a major component of the coral skeleton (Mollica et al., 2018). Coral reef calcification rate, the rate of skeleton formation using calcium carbonate, is sensitive to carbonate saturation in water bodies, which is reduced as $\mathrm{CO}_{2}$ concentrations increase. Thus, ocean acidification makes it harder for corals to build their skeletal structure (See Fig. 1; Jiang et al., 2019). A numerical model of Porites corals' skeletal growth projected that the skeletal density of these corals could decline by around $20.3 \%$ over the 21 st century due to ocean acidification (Mollica et al., 2018). Reduced skeletal density increases reef vulnerability to physical damage, bioerosion and predation, and reduces their ability to compete for space (Scavia et al., 2002). This suggests that in the future, corals may be more susceptible to diseases and bioerosion. 
Schneider and Erez (2006) have provided experimental support for the negative impact of ocean acidification on corals. They placed the coral Acropora erystoma in a seawater preparation and manipulated the rates of different carbonate chemistry parameters, including $\mathrm{pH}$. They found that calcification increased with increased carbonate concentration, and decreased by $50 \%$ when exposed to a $30 \%$ decrease in carbonate levels, which is equivalent to a decrease in $\mathrm{pH}$ by 0.2 units (Schneider \& Erez, 2006). With the current rate of decrease in seawater $\mathrm{pH}$ of 0.02-0.04 units per decade, this is particularly disconcerting.

\section{Physiological Responses of Coral Reefs to Climate Change Threats}

Responses to Elevated Temperatures. Corals may be able to adapt to elevated sea surface temperature (SST) by exchanging their zooxanthellae for a heat-tolerant variety. There is some evidence that this exchange occurs in nature. Baker and colleagues (2004) have found this effect in at least five locations in the Indo-Pacific. They undertook molecular surveys of the zooxanthellae and found that thermally tolerant species are more abundant in reefs after episodes of severe bleaching or mortality. The surviving symbioses closely resemble those found in high-temperature environments (Baker et al., 2004). Thus, adaptation may be a response to increasing SST, but further research is required to determine which species are able to adapt to the current rate of climate change.

Previous research related to the bleaching phenomenon has largely focused on adult coral reef organisms (Mies et al., 2018). Thus, the impact of bleaching is poorly understood for reef species in larval stages. A better understanding of the resilience and thermo-tolerance of hosts and their symbionts in the larval stages may prove important for the development of conservation strategies and assessments of climate change scenarios. Mies et al. (2018) exposed larvae within zooxanthellae (Symbiodinium spp.) clades A-F, which were associated with 3 different hosts including the coral Mussismilia hispida, to temperatures of $26^{\circ} \mathrm{C}, 29^{\circ} \mathrm{C}$ and $32^{\circ} \mathrm{C}$. They observed that the host larvae species exhibited different bleaching rates based on the zooxanthellae types. For the larvae of coral M. Hispida, the bleaching threshold was $29^{\circ} \mathrm{C}$, which is lower than $31^{\circ} \mathrm{C}$ for adult organisms. However, while all corals were bleached at $32^{\circ} \mathrm{C}$, coral larvae associated with Symbiodinium type A1 bleached significantly less, suggesting that type A1 is relatively thermo-tolerant. This is different from the several reports that the Symbiodinium clade D strains are more thermo-tolerant in adult hosts (Mies et al., 2018; Silverstein, Cunning, \& Baker, 2017). Thus, studies on hosts in larval stages could provide crucial information for conservationists. 
Responses to Ocean Acidification. Some coral reef organisms are able to modulate physiological responses to ocean acidification. Recent research suggests that facilitation (i.e. interaction with other organisms under crowded conditions that positively affects the organisms involved) allows organisms to maximize this capacity (Evensen \& Edmunds, 2017). Evensen and Edmunds (2017) investigated whether colony density and coral-coral interactions affect coral growth under ocean acidification conditions. They exposed 12 colonies of coral Pocillopora verrucosa, placed $\sim 0.5 \mathrm{~cm}$ versus $\sim 8 \mathrm{~cm}$ apart, to varying partial pressures of $\mathrm{CO}_{2}$ $\left(\mathrm{PCO}_{2} ; \sim 400 \mu \mathrm{atm}\right.$ and $\left.\sim 1200 \mu \mathrm{atm}\right)$. They observed a $20 \%$ decrease in calcification rate in low-density aggregations, but a $23 \%$ increase in high-density aggregations at elevated as compared to ambient $\mathrm{PCO}_{2}$ in light conditions. While high-density aggregations experienced a $45 \%$ decrease in calcification in the dark, they were able to maintain calcification rates comparable to the rate at ambient $\mathrm{PCO}_{2}$ over a 24-hour time period (Evensen \& Edmunds, 2017). This suggests that establishing highdensity colonies of corals may help protect them from the negative effects of ocean acidification.

Some species of corals may be able to buffer $\mathrm{pH}$ changes to protect against the effects of coral acidification. Scleractinian corals upregulate $\mathrm{pH}$ at their site of calcification, which enables them to increase calcification rates, thereby ameliorating the effects of ocean acidification (McCulloch, Falter, Trotter, \& Montagna, 2012). Identifying and researching these species may be useful in preserving the coral reefs in the future.

Responses to Interactive Effects of Ocean Warming and Acidification. Colony size and coral-coral interactions seem to be important considerations when evaluating responses to ocean warming and acidification (OWA). However, they have been largely overlooked in previous studies (Edmunds \& Burgess, 2016). Edmunds and Burgess (2016) exposed the branching coral Pocillopora verrucose $(2.0$ to $13.1 \mathrm{~cm}$ diameter) across a range of colony sizes to varying $\mathrm{PCO}_{2}(\sim 400$ and $\sim 1000 \mu \mathrm{atm})$ and temperatures $\left(\sim 26.5\right.$ and $\left.\sim 29.7^{\circ} \mathrm{C}\right)$. They observed that large corals calcified more, but at a slower size-specific calcification rate as compared to small corals (i.e. tissue surface area-normalized rates decreased with size). However, the net calcification of $P$. verrucose in the colonies was unaffected by temperature and $\mathrm{PCO}_{2}$. This is in contrast with previous findings that net calcification is depressed by high $\mathrm{PCO}_{2}$ in small coral nubbins (Comeau et al., 2014). In another study, Edmunds and Burgess (2020) exposed intact colonies of coral Acropora hyacinthus $(4.6$ to $19.9 \mathrm{~cm}$ diameter), reflecting naturally occurring colony sizes, to similar OWA treatments. They found that net calcification of these colonies was also unaffected. This suggests that responses of branching corals are size-dependent and that net calcification 
of intact colonies of branching corals, such as $P$. verrucose and $A$. hyacinthus, may be resistant to the combined effects of OWA (Edmunds \& Burgess, 2020). Additionally, these results have implications in experimental research on coral biology, which is dominated by experiments with coral nubbins that seem to be functionally different and more sensitive to these environmental stressors as compared to intact colonies.

Coral reefs respond differently to thermal stress and bleaching events, partly based on their location, which determines local heat exposure and adaptations to different conditions over evolutionary time scales (Hughes et al., 2018). For instance, during the 2016 heatwave, the southern region of the Great Barrier Reef experienced only minor bleaching, because the summer temperatures were close to average. However, in its northern region, hundreds of reefs were severely bleached (Hughes et al., 2018). This suggests that there is a need to identify areas that can serve as temporary refugia for corals and other species supported by coral reefs under changing environmental threats. Guan et al. (2020) analyzed the coral reef habitat suitability across the tropics in relation to increases in temperature $\left(0.1^{\circ} \mathrm{C}\right)$, nitrate levels $(0.02 \mu \mathrm{mol} / \mathrm{L})$, and phosphate levels (0.01 $\mu \mathrm{mol} / \mathrm{L})$, as well as a decrease in aragonite saturation (0.04 units), by using normalized frequency distribution of reef counts as a proxy for habitat suitability. They predicted that only $6 \%$ of reefs worldwide would be unaffected by these stressors. These areas could act as climate change coral refugia until these stressors can be minimized.

Recent research on corals in the larval stage has also provided insights into various ways through which corals may acclimate (i.e. accommodate environmental stressors through temporary physiological changes). Putnam and Gates (2015) found that preconditioning in corals has a potential for transgenerational acclimation in coral larvae under future climate change conditions. The researchers exposed the adult coral Pocillopra damicornis to either a high $\left(28.9^{\circ} \mathrm{C}, 805\right.$

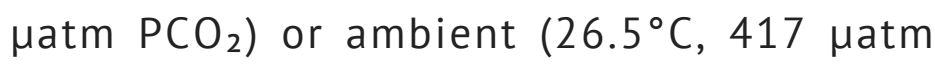
$\left.\mathrm{PCO}_{2}\right)$ OWA treatment during the larval brooding period. They discovered that the high treatment negatively affected adult performance, but their larvae showed metabolic acclimation when re-exposed to harsh conditions (Putnam \& Gates, 2015). This suggests that parental effects which occur when the phenotype of offspring is affected by parental phenotype or environment - and non-genetic inheritance may have an important role in acclimation, and can be targeted for the conservation of corals (Bellworthy et al., 2019; Putnam \& Gates, 2015).

Transgenerational acclimation seems to be a major factor in determining the ability of coral reefs to survive in the face of climate change. Yet, research on carryover effects in corals in relation to climate change is 
lacking (Bellworthy et al., 2019). Carryover effects include parental effects and developmental acclimation of the offspring, the planulae, to the environment during brooding. Consideration of carryover and transgenerational effects can help determine if a location could serve as a future climate change coral refugium by ensuring that multigenerational exposure to the same stressors does not negatively impact the coral population. Bellworthy et al. (2019) exposed mature colonies of coral Stylophora pistillata from the Gulf of Aqaba, a potential coral refugium, to seawater conditions simulating the conditions likely to occur at the beginning of the 22 nd century during brooding $(\mathrm{pH}$ : $\left.-0.4,+5^{\circ} \mathrm{C}\right)$, in order to thoroughly assess the potential of this site as a refugium. They observed that after 5 weeks of exposure to future OWA conditions, the planulae S. Pistillata exhibited few treatment-induced differences, indicating weak climate-related carryover effects and suggesting that this species may be resistant to the effects of OWA (Bellworthy et al., 2019). This study provides support for the Gulf of Aqaba to serve as a future refugium for the corals in response to the devastating impacts of climate change.

\section{Conclusion}

Anthropogenic climate change is a serious threat to the persistence of coral reefs. The major threats to corals are increasing sea surface temperatures and ocean acidification, which can lead to bleaching and reduction in calcification and seriously affect the health of the corals (Mies et al., 2018; Mollica et al., 2018). If climate change or warming is not mitigated, bleaching events may exceed the frequency at which corals can recover from bleaching-related mortality (Hoegh-Guldberg, 1999).

Research over the past decade on the persistence and resilience of particular coral reef species has provided crucial information about potential refugia and thermo-tolerant species, which would allow for the development of efficient, updated conservation strategies (Guan et al., 2020; Mies et al., 2018). This is especially important as the latter half of the decade has observed unprecedented extreme temperatures which have already severely impacted most coral reefs (Heron et al., 2016).

Future research should explore the capacities of coral and zooxanthellae species to adapt or acclimate to the rapid changes in SST and $\mathrm{pH}$ projected by climate change models. Particularly, research on transgenerational acclimation and $\mathrm{pH}$ buffering capacity of corals, and experimentation with intact coral colonies would inform which species are more likely to persist in this rapidly changing climate. Research priority should be the investigation of coral reef species identified as resistant to OWA, as well as areas identified as potential refugia for corals, such as the Gulf of Aqaba. 
This would allow conservationists to use the data to develop conservation and restoration strategies to minimize the impacts of climate change on coral reefs. 


\section{References}

Baker, A. C., Starger, C. J., McClanahan, T. R., \& Glynn, P. W. (2004). Corals' adaptive response to climate change. Nature, 430, 741. https://doi.org/10.1038/430741a

Bellworthy, J., Menoud, M., Krueger, T., Meibom, A., \& Fine, M. (2019). Developmental carryover effects of ocean warming and acidification in corals from a potential climate refugium, the Gulf of Aqaba. Journal of Experimental Biology, 222(1). https://doi.org/10.1242/jeb.186940

Comeau, S., Edmunds, P. J., Spindel, N. B., \& Carpenter, R. C. (2014). Fast coral reef calcifiers are more sensitive to ocean acidification in short-term laboratory incubations. Limnology and Oceanography, 59(3), 1081-1091. https://doi.org/10.4319/lo.2014.59.3.1081

Edmunds, P. J., \& Burgess, S. C. (2016). Size-dependent physiological responses of the branching coral Pocillopora verrucosa to elevated temperature and $\mathrm{PCO}_{2}$. Journal of Experimental Biology, 219(24), 3896-3906. https://doi.org/10.1242/jeb.146381

Edmunds, P. J., \& Burgess, S. C. (2020). Emergent properties of branching morphologies modulate the sensitivity of coral calcification to high $\mathrm{PCO}_{2}$. Journal of Experimental Biology, 223(8). https://doi.org/10.1242/jeb.217000

Evensen, N. R., \& Edmunds, P. J. (2017). Conspecific aggregations mitigate the effects of ocean acidification on calcification of the coral Pocillopora verrucosa. Journal of Experimental Biology, 220(6), 1097 - 1105. https://doi.org/10.1242/jeb.152488

Guan, Y., Hohn, S., Wild, C., \& Merico, A. (2020). Vulnerability of global coral reef habitat suitability to ocean warming, acidification and eutrophication. Global Change Biology, 26(10), 5646-5660. https://doi.org/10.1111/gcb.15293

Heron, S. F., Maynard, J. A., van Hooidonk, R., \& Eakin, C. M. (2016). Warming trends and bleaching stress of the world's coral reefs 1985-2012. Scientific Reports, 6(1), 1-14. https://doi.org/10.1038/srep38402

Hillyer, K. E., Tumanov, S., Villas-Bôas, S., \& Davy, S. K. (2016). Metabolite profiling of symbiont and host during thermal stress and bleaching in a model cnidariandinoflagellate symbiosis. Journal of Experimental Biology, 219(4), 516-527. https://doi.org/10.1242/jeb.128660 
Hoegh-Guldberg, O. (1999). Climate change, coral bleaching and the future of the world's coral reefs. Marine and Freshwater Research, 50(8), 839-866. https://doi.org/10.1071/MF99078

Hoegh-Guldberg, O., \& Bruno, J. F. (2010). The impact of climate change on the world's marine ecosystems. Science, 328(5985), 1523-1528. https://doi.org/10.1126/science.1189930

Hughes, T. P., Kerry, J. T., \& Simpson, T. (2018). Large-scale bleaching of corals on the Great Barrier Reef. Ecology, 99(2), 501-501. https://doi.org/10.1002/ecy.2092

Jiang, L. Q., Carter, B. R., Feely, R. A., Lauvset, S. K., \& Olsen, A. (2019). Surface ocean pH and buffer capacity: Past, present and future. Scientific Reports, 9(1), 1-11. https://doi.org/10.1038/s41598-019- 55039-4

McCulloch, M., Falter, J., Trotter, J., \& Montagna, P. (2012). Coral resilience to ocean acidification and global warming through pH up-regulation. Nature Climate Change, 2(8), 623-627. https://doi.org/10.1038/nclimate1473

Mies, M., Güth, A. Z., Castro, C. B., Pires, D. O., Calderon, E. N., Pompeu, M., \& Sumida, P. Y. G. (2018). Bleaching in reef invertebrate larvae associated with Symbiodinium strains within clades A-F. Marine Biology, 165(1). https://doi.org/10.1007/s00227-017-3263-1

Mollica, N. R., Guo, W., Cohen, A. L., Huang, K. F., Foster, G. L., Donald, H. K., \& Solow, A. R. (2018). Ocean acidification affects coral growth by reducing skeletal density. Proceedings of the National Academy of Sciences of the United States of America, 115(8), 1754-1759. https://doi.org/10.1073/pnas.1712806115

National Centers for Environmental Information. (2020). Global Climate Report - Annual 2019. https://www.ncdc.noaa.gov/sotc/global/201913

Putnam, H. M., \& Gates, R. D. (2015). Preconditioning in the reef-building coral Pocillopora damicornis and the potential for trans-generational acclimatization in coral Larvae under future climate change conditions. Journal of Experimental Biology, 218(15), 2365-2372. https://doi.org/10.1242/jeb.123018 
Scavia, D., Field, J. C., Boesch, D. F., Buddemeier, R. W., Burkett, V., Cayan, D. R., Fogarty, M., Harwell, M. A., Howarth, R. W., Mason, C., Reed, D. J., Royer, T. C., Sallenger, A. H., \& Titus, J. G. (2002). Climate change impacts on U.S. coastal and marine ecosystems. Estuaries, 25(2), 149-164. https://doi.org/10.1007/BF02691304

Schneider, K., \& Erez, J. (2006). The effect of carbonate chemistry on calcification and photosynthesis in the hermatypic coral Acropora eurystoma. Limnology and Oceanography, 51(3), 1284-1293. https://doi.org/10.4319/lo.2006.51.3.1284

Silverstein, R. N., Cunning, R., \& Baker, A. C. (2017). Tenacious D: Symbiodinium in clade $D$ remain in reef corals at both high and low temperature extremes despite impairment. Journal of Experimental Biology, 220(7), 1192-1196. https://doi.org/10.1242/jeb.148239

von Schuckmann, K., Palmer, M. D., Trenberth, K. E., Cazenave, A., Chambers, D., Champollion, N., Hansen, J., Josey, S. A., Loeb, N., Mathieu, P.-P., Meyssignac, B, \& Wild, M. (2016). An imperative to monitor Earth's energy imbalance. Nature Climate Change, 6(2), 138 -144. https://doi.org/10.1038/nclimate2876 